\title{
BMJ Open Cohort profile: COpenhagen ROsacea COhort (COROCO) and COpenhagen MIgraine COhort (COMICO)
}

\author{
Nita Katarina Frifelt Wienholtz (1) , , ${ }^{1,2}$ Casper Emil Christensen, ${ }^{2}$ \\ Jeanette Halskou Haugaard, ${ }^{1}$ Ditte Georgina Zhang, ${ }^{2}$ Messoud Ashina, ${ }^{2}$ \\ Jacob Pontoppidan Thyssen, ${ }^{1}$ Alexander Egeberg ${ }^{1}$
}

To cite: Wienholtz NKF, Christensen CE, Haugaard JH, et al. Cohort profile: COpenhagen R0sacea COhort (COROCO) and COpenhagen Mlgraine COhort (COMICO). BMJ Open 2020;10:e039445. doi:10.1136/ bmjopen-2020-039445

- Prepublication history and additional material for this paper are available online. To view these files, please visit the journal online (http://dx.doi. org/10.1136/bmjopen-2020039445).

Received 15 April 2020 Revised 14 July 2020 Accepted 16 July 2020
Check for updates

(c) Author(s) (or their employer(s)) 2020. Re-use permitted under CC BY-NC. No commercial re-use. See rights and permissions. Published by BMJ.

${ }^{1}$ Department of Dermatology and Allergy, Herlev and Gentofte Hospital, University of Copenhagen, Hellerup, Denmark; Copenhagen Research Group for Inflammatory Skin (CORGIS), Herlev and Gentofte Hospital, Hellerup, Denmark ${ }^{2}$ Danish Headache Center, Department of Neurology, Rigshospitalet Glostrup, Faculty of Health and Medical Sciences, University of Copenhagen, Glostrup, Denmark

Correspondence to Dr Alexander Egeberg; alexander.egeberg@gmail.com

\section{ABSTRACT}

Purpose Migraine has consistently been connected with rosacea. Commonalities in epidemiology, trigger factors and associated neuropeptides support shared aetiology and pathophysiological pathways, though underlying mechanisms remain unclear. We established two cohorts of patients diagnosed with either migraine and/or rosacea. All patients were phenotyped in regard to migraine and rosacea. In this article, we describe the baseline parameters of the cohorts. In the future, we expect that these cohorts will help uncover potential disease overlaps and allow for prolonged follow-up through national Danish health registers.

Participants COpenhagen ROsacea COhort (COROCO) and COpenhagen Mlgraine COhort (COMICO) are prospective cohorts based in the Capital region of Denmark.

Participants for COROCO were recruited primarily through two tertiary dermatology clinics in Copenhagen, Denmark and patients for COMICO were recruited through a tertiary neurology clinic in Copenhagen, Denmark.

Findings to date COROCO: $67.7 \%$ women (median age 51 years (interquartile range (IQR) 43.0-61.0)). Family history of migraine: $44.3 \%$. Family history of rosacea: $45 \%$. There were $13 \%$ who currently smoked, and $36.6 \%$ were former smokers. Regular intake of alcohol was present in 79.3\% (median 4 items/week (IQR 1.0-9.0)). Median body mass index (BMI): 25.7 (IQR 23.1-29.0). Median Dermatology Life Quality Index (DLQI): 2 (IQR 1-5). COMICO: 88.5\% women (median age 41 years (IQR 29.5$51.0)$ ). Family history of migraine: $73.4 \%$. Family history of rosacea: $18.4 \%$. There were $17.1 \%$ who currently smoked, and $26.0 \%$ former smokers. Regular intake of alcohol was present in $62.2 \%$ (median intake: 2 item/week (IQR 1.0-3.0)). Median BMI was 24.6 (IQR 21.5-28.2). Median DLQI was 1 (IQR 0-2).

Future plans COROCO and COMICO serve as strong data sources that will be used for future studies on rosacea and migraine with focus on risk factors, occurrence, treatment, natural history, complications, comorbidities and prognosis.

Trial registration number ClinicalTrials.gov Registry (NCT03872050).

\section{INTRODUCTION}

Migraine has repeatedly been associated with rosacea. ${ }^{1}$ Both are chronic inflammatory

\section{Strengths and limitations of this study}

- Copenhagen Rosacea Cohort and Copenhagen Migraine Cohort are large cohorts of adults with physician-diagnosed migraine or rosacea that are phenotyped through the face-to-face interview by trained professionals.

- Rosacea diagnoses are validated through pictures evaluated by three physicians, and migraine diagnoses validated through semi-structured interviews.

- Collected information includes pictures with normal and thermal cameras, blood samples, inflammatory markers, and DNA for a thorough description of each participant.

- Future linkage to Danish national health registers enables us to follow patients for a prolonged period of time.

- Limitations include risk of selection bias as participants are recruited from speciality units, and risk of recall bias as the cohorts are based on interviews.

conditions with relapsing episodes of headache for migraine, and redness/flushing and/ or papules/pustules for rosacea. Relapses may be triggered by various endogenous and/or exogenous factors such as different foods and drinks, exercise, sun/UV exposure, heat and stress. ${ }^{23}$ Migraine is common with a prevalence of $12 \%,{ }^{4}$ and up to $18.3 \%$ in women. ${ }^{4-6}$ Migraine seems to be underdiagnosed and undertreated ${ }^{67}$ and the actual prevalence is probably higher. Rosacea has an overall prevalence of $5.5 \%$ and usually affects individuals above the age of 30 years. ${ }^{8}$ The disorders are primarily seen in individuals of Caucasian descent. ${ }^{48}$ Aetiology for both is largely unknown, but seems to involve a mix of genetic and environmental factors. ${ }^{10} 11$ Other commonalities between migraine and rosacea include neuroinflammation and upregulation of signalling neuropeptides, such as pituitary adenylate cyclase-activating polypeptide- $38^{2} 12$ and calcitonin generelated peptide (CGRP) ${ }^{13}{ }^{14}$ though there are 
other suggested signalling pathways for both disorders. ${ }^{10}$ Common demography, triggers and associated neuropeptides suggest a shared pathophysiological pathway. ${ }^{1}$

Despite overwhelming evidence of a connection between migraine and rosacea,${ }^{15-20}$ underdiagnosis in both disorders must be considered as a confounder in previous research, and a systematic approach is therefore needed to confirm this connection and to better characterise exact overlap between these diseases. Establishment of prospective patient cohorts with a physiciandiagnosis of either migraine or rosacea will help confirm this connection and uncover possible risk factors and comorbidities in both.

\section{COHORT DESCRIPTION}

\section{Study population and setting}

Two cohorts were established; COpenhagen ROsacea COhort (COROCO) and COpenhagen MIgraine COhort (COMICO). Willing participants had to be aged 18 years or above. A physician-diagnosis of rosacea was needed to be included in COROCO, and a physician-diagnosis of migraine was needed to be included in COMICO. There were no exclusion criteria. All participants signed an informed consent form upon enrolment.

\section{Recruitment}

\section{Copenhagen Rosacea Cohort}

Electronic medical records (EMRs) were searched for adults who consulted a doctor for a diagnosis of rosacea at either Department of Dermatology and Allergy at Gentofte Hospital (between 3 September 2013 and 5 May 2019) or Department of Dermatology and Wound Healing Centre at Bispebjerg Hospital (between 1 January 2014 and 21 November 2018). Diagnosis of rosacea was defined as one of the following International Classification of Diseases and Related Health Problems(ICD)-10 codes: DL71, DL718A, DL719 and DL718. ${ }^{21}$

A total of 790 patients were identified through EMR and invited to participate in the rosacea cohort. Five letters were not delivered due to the wrong address, and invitations were thus delivered to 785 patients. Patients could respond through one of three routes: mailing the 'return envelope' (free of charge), sending an e-mail or calling/texting a dedicated phone. The response rate was $46.8 \%$ (367 patients). Nine patients informed us that they did not want to participate due to illness, lack of time or because they did not believe to have rosacea. Of the 358 patients who responded positively to the invitation, we interviewed 274 patients before reaching the prespecified inclusion number (see figure 1 for details). An additional 35 patients with a prior diagnosis of rosacea were included via the Danish Headache Center at Rigshospitalet Glostrup or via online recruitment (www.forsø gsperson.dk). Interviews were performed in 309 patients, and after reviewing pictures, nine patients were excluded from analysis, as their signs could not clearly be attributed to rosacea. COROCO thus included a total of 300 patients.
Interviews were performed between 17 September 2018 and 14 October 2019.

\section{Copenhagen Migraine Cohort}

Patients for COMICO were recruited through the Danish Headache Center, Department of Neurology at Rigshospitalet Glostrup, Copenhagen, Denmark. The Danish Headache Center is a tertiary care facility for patients with persistent or difficult-to-treat headaches who have been referred by either a general practitioner or from a specialist neurology clinic. Patients were asked to participate when they came for an outpatient visit at the headache centre. A physician-diagnosis of migraine (with or without aura) was necessary for inclusion. In all, 281 patients were recruited from the Danish Headache Center. An additional 23 patients were recruited online (www.forsøgsperson.dk) (see figure 2 for details). A total of 304 patients were included in COMICO. Interviews were performed between 14 September 2018 and 29 October 2019.

\section{Study visit}

Patients were seen once during the study period. The visit took place at one of three locations of the patient's choice: Danish Headache Center (Rigshospitalet Glostrup), Department of Dermatology (Gentofte hospital) or by home visit at the patient's home/work.

The entire visit; both interviews and clinical examination, was performed by either a medical doctor (author NKFW) or by senior medical students who were specifically trained to perform both.

Each visit lasted approximately $60 \mathrm{~min}$ and included the interview, blood sample, pictures with digital and thermal cameras, superficial stratum corneum sampling of the forearm and cheek, and mouth swab for DNA sampling. Procedures are described below. Patients only had to agree to the semi-structured interview to be eligible for the study, as this was the essential part of the investigation; however, most patients agreed to all investigations.

\section{Interview}

A semi-structured interview was performed at the beginning of the visit based on two questionnaires. All participants were asked questions on both rosacea and migraine to confirm diagnosis and phenotype. All questionnaires were reviewed by author NKFW. In case of doubt about rosacea diagnosis, authors AE and JPT were consulted, and in case of doubt about migraine diagnosis, author MA was consulted.

\section{Questionnaire: rosacea}

Demographic information, comorbidities, family history of rosacea, Dermatology Life Quality Index (DLQI) and presence of rosacea features were collected. If patients had a prior diagnosis of rosacea, first presenting sign or symptom of rosacea, diagnostic delay and previous treatments were also collected (online supplementary appendix 1). Patients were also evaluated with the National Rosacea Society Rosacea Clinical Scorecard. ${ }^{22}$ 
377 identified through EMR

(Dept. of Dermatology and Allergy and Gentofte Hospital)
413 identified through EMR (Dept. of Dermatology and Wound healing at Bispebjerg Hospital)

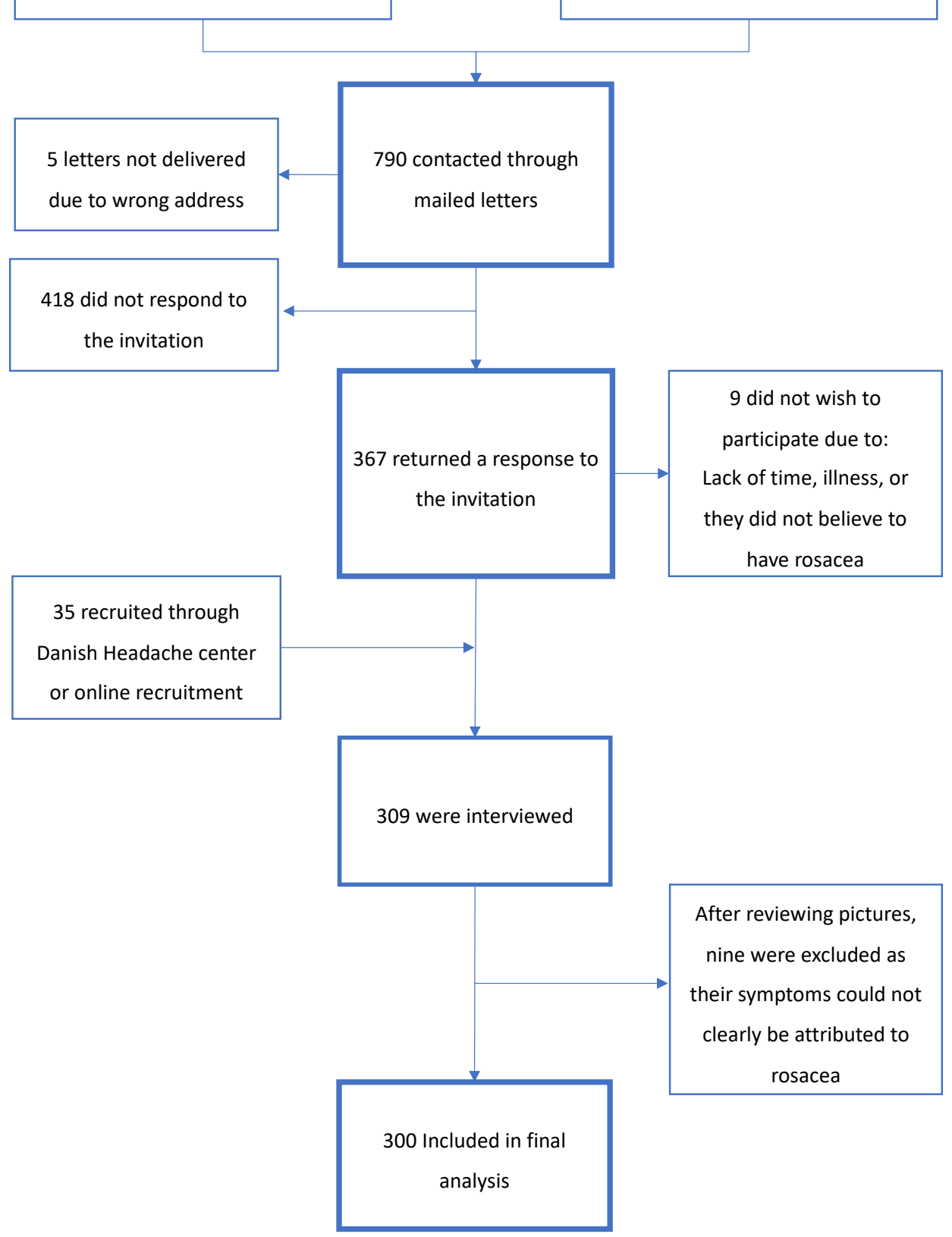

Figure 1 Flowchart detailing enrolment in Copenhagen Rosacea Cohort. EMR, electronic medical records. 


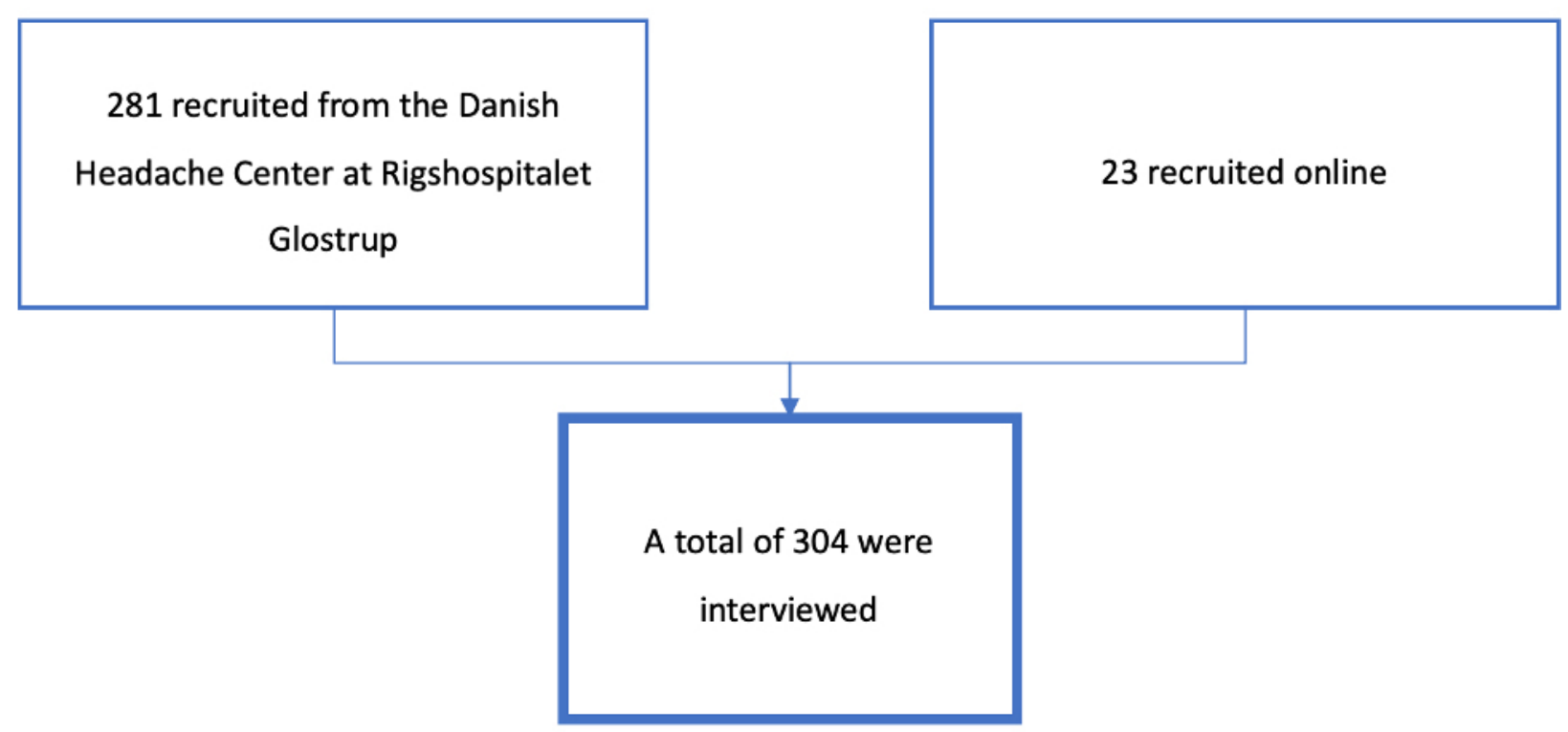

Figure 2 Flowchart detailing enrolment in Copenhagen Migraine Cohort.

Questionnaire: migraine

A validated semi-structured questionnaire on diagnosis and subtyping of migraine ${ }^{23}$ was adapted by author NKFW for the purpose of interviewing patients with no known migraine or headache (online supplementary appendix 2 ). Questions included family history of migraine, headache/migraine and aura symptoms along with risk factors for headache/migraine. All patients, also, those who claimed to have a previous diagnosis of migraine, were asked about headache characteristics to validate migraine diagnosis. If patients fulfilled the criteria for a diagnosis of migraine, migraine onset and headache frequency were collected.

\section{CLINICAL EXAMINATION}

The following examinations were performed after the interview, and patients had therefore been sitting calmly for at least $30 \mathrm{~min}$ and drinking nothing but water, prior to examinations.

All examinations were performed in patients included in both COROCO and COMICO.

\section{Standardised photography}

A standardised picture was taken with a digital Canon PowerShot G12 camera at a distance of approximately $70 \mathrm{~cm}$, with a flash and zoom when needed. Pictures were rated according to phenotype and the newly developed rosacea scoring tool 'Rosacea Area and Severity Index' (manuscript in development), to ensure correct diagnosis and classification of rosacea.

All pictures were evaluated by three authors (JPT, AE, NKFW). Disagreements were resolved by discussion. In cases of doubt, patients were rated as 'not rosacea' or 'non-classifiable'. These ratings will be compared with interview data in a future publication, to evaluate the validity of both.

\section{Thermography}

Thermographic pictures were recorded after patients had been placed in a room with a stable temperature for at least $15 \mathrm{~min}$. Pictures were recorded on FLIR ${ }^{\circledast}$ A655sc with a $25^{\circ}$ lens. The camera has a range of $-40^{\circ} \mathrm{C}$ to $+150^{\circ} \mathrm{C}$ and temperature accuracy of $\pm 1^{\circ} \mathrm{C}$. Pictures were recorded at a distance of approximately $50 \mathrm{~cm}$ from the subject. For each subject, a total of three pictures were recorded-one picture from the front and one from each side. The FLIR ${ }^{\circledR}$ program ResearchIR (Max 4) was used to record pictures. Analyses were performed in the program FLIR ${ }^{\circledR}$ TOOLS. The temperature was measured at each side of the face corresponding to the facial area of the three branches of the trigeminus (forehead, cheeks and chin). An additional temperature measurement was performed on the tip of the nose (online supplementary figure 1). The measure point was matched to the size of the iris to adjust for differences in distances from which the pictures were taken.

Facial skin temperature has previously been investigated in both migraine and rosacea with unclear results. ${ }^{24} \mathrm{We}$, therefore, offer baseline temperatures in a large group of patients with both disorders to determine whether previous findings reflect true differences or simply interindividual differences within patient groups.

\section{Superficial stratum corneum sampling}

A sample of stratum corneum was collected using the tape stripping method. Samples were collected from two sites (one forearm and one cheek), Seven consecutive tape stripping discs $(22 \mathrm{~mm})$ (D-squame, CuDerm, Dallas, Texas, USA) were collected from each site. Discs were applied with tweezers followed by a standardised pressure with a D-squame pressure application pen for $5 \mathrm{~s}$. The first three discs from each site were discarded, and the following four discs were stored at $-80^{\circ} \mathrm{C}$ immediately 
after sampling. The discs will be examined for cytokines and skin microbiome.

Rosacea is characterised by local inflammation of the face; however, recent evidence suggests that the inflammation may be systemic. ${ }^{25}$ Migraine has also been suggested to involve especially neuroinflammation, but possibly also systemic inflammation. ${ }^{26}$

Measurement of inflammatory markers in the skin will allow us to compare facial inflammation (cheek) to systemic inflammation (forearm) and to compare patients with migraine and rosacea to uncover a possible subclinical inflammation in both disorders. Furthermore, we hope to investigate whether there is a correlation between local/systemic inflammation, subtypes of rosacea and disease activity.

\section{Genetics}

Patients were not allowed to eat, drink, smoke, chew gum or clean teeth 1 hour before collection. All patients were instructed to rinse their mouth with water immediately prior to collection. For the analyses, one SK-1S DNA buccal swab (Isohelix, Harrietsham, UK) was rubbed against cheek mucosa for $60 \mathrm{~s}$ before returning the swab to the supplied tube without touching the head of the swab. The shaft was broken on the edge of the tube which left the head of the swab in the tube. The tube was stored at $-80^{\circ} \mathrm{C}$ until analysis.

The purpose of DNA collection was to perform a genome-wide association-study (GWAS) for the most common gene mutations in rosacea and migraine. A large meta-analysis of 375000 individuals has located 38 loci relevant for migraine, ${ }^{27}$ whereas GWAS has only been done a few times in rosacea and only on populations selected from the '23andMe' customer base. ${ }^{28}{ }^{29} \mathrm{We}$ will look at loci relevant to both migraine and rosacea in both patients groups to discover any potential overlaps. The analysis will not include genes listed on the American College of Medical Genetics and Genomics (ACMG) recommendations for reporting of incidental findings in clinical exome and genome sequencing. ${ }^{30}$

\section{Blood sample}

A blood sample was collected from a cubital vein (Vacuette Safety Blood Collection Set) into three $9 \mathrm{~mL}$ EDTA tubes (Vacuette $\mathrm{K}_{2}$ EDTA) which were each inverted 10 times immediately after collection to let blood mix with the separator gel. Samples were kept at room temperature (between 20 and $24^{\circ} \mathrm{C}$ ) and within 60 min of sampling, full blood was transferred with a pipette (Alpha Laboratories pipette standard micro sterile pastette) from one EDTA tube into $2-42.0 \mathrm{~mL}$ cryo vials (IVUS). The two remaining EDTA tubes were centrifuged (Hettich Zentrifugen EBA 20) at $2500 \mathrm{rpm}$ for $5 \mathrm{~min}$ to separate plasma. Plasma was then transferred (Alpha Laboratories pipette standard micro sterile pastette) into $2-42.0 \mathrm{~mL}$ cryo vials (IVUS) and 2-4 $2.0 \mathrm{~mL}$ cryo vials (IVUS) with Thermo scientific protease inhibitor $(10 \mu \mathrm{L}$ per $\mathrm{mL}$ of plasma). All samples were stored at $-80^{\circ} \mathrm{C}$ until analysis.
The purpose of the blood sample was to analyse samples for CGRP. CGRP is a signalling neuropeptide which has previously been linked to both migraine ${ }^{31}$ and rosacea ${ }^{32}$ and has been suggested to be related to disease pathology. CGRP is relatively well-described in migraine, and CRGPantibodies have recently proven beneficial in the preventive treatment of migraine. ${ }^{33}$

By stratifying CGRP measurements in this project we hope to be able to uncover a possible relationship between CGRP, subtypes and disease activity in especially rosacea.

\section{Findings to date}

Findings are summarised in table 1 for COROCO and table 2 for COMICO.

\section{Copenhagen Rosacea Cohort \\ Age and sex}

Median age was 51 years (IQR 43.0-61.0) and there were $67.7 \%$ women in the cohort.

Rosacea usually affects individuals above age 30 years ${ }^{9}$ with a peak onset between 45 and 60 years. ${ }^{8}$ The sex distribution is more or less even, with only a tendency towards a female predominance. ${ }^{8}$ COROCO thus resembles previous studies in rosacea.

\section{Family history of migraine}

Family history of migraine was present in $44.3 \%$ of the rosacea cohort.

Family history of migraine in the general population is usually under-reported, ${ }^{34}{ }^{35}$ which may contribute to the low prevalence of family history of migraine in our rosacea cohort.

\section{Family history of rosacea}

Family history of rosacea was $45 \%$ in the rosacea cohort.

Family history of rosacea in patients with rosacea has previously been reported in up to $55 \%$, compared with $12 \%-17 \%$ in controls. ${ }^{36}{ }^{37}$ Rosacea is largely underestimated and often goes undiagnosed, ${ }^{17} 3839$ contributing to low family history reports of rosacea. In our cohort, some patients stated that they suspected family members of having rosacea, but only definite diagnoses were included in our analysis, probably underestimating family history of rosacea.

\section{Smoking}

There were $13.0 \%$ current smokers in COROCO. The median pack-years for smokers were 24.6 years (IQR 13.3-36.0). A total of $36.6 \%$ were former smokers.

Smoking in rosacea is debated. Some studies find a lower prevalence of smoking in patients with rosacea, ${ }^{40} 41$ and find current smoking to be protective against incident rosacea, ${ }^{42}$ whereas others find a higher prevalence of smoking. ${ }^{43}{ }^{44}$ Smoking constricts the peripheral blood vessels, possibly masking rosacea which could be a reason why we see a lower prevalence of current smoking in the rosacea group. Interestingly, past smoking has been associated with a higher risk of incident rosacea compared 


\begin{tabular}{|c|c|c|}
\hline & $\mathbf{N}$ & COROCO (Rosacea) \\
\hline Age, median (IQR) & 300 & $51.0(43.0-61.0)$ \\
\hline Sex, n (\%) & 300 & \\
\hline Men & & $97(32.3)$ \\
\hline Women & & $203(67.7)$ \\
\hline $\begin{array}{l}\text { Family history of rosacea, } \\
\mathrm{n}(\%)\end{array}$ & 300 & \\
\hline Any family member & & $135(45.0)$ \\
\hline First degree relative & & $124(41.3)$ \\
\hline $\begin{array}{l}\text { Second and third degree } \\
\text { relative }\end{array}$ & & $30(10.0)$ \\
\hline
\end{tabular}

\section{Family history of migraine, 300 $\mathrm{n}(\%)$}

$\begin{array}{ll}\text { Any family member } & 133(44.3) \\ \text { First degree relative } & 117(39.0) \\ \text { Second and third degree } & 37(12.3)\end{array}$
relative

\begin{tabular}{|c|c|c|}
\hline Smoking, n (\%) & 300 & \\
\hline Never & & $151(49.8)$ \\
\hline Former smoker & & $111(36.6)$ \\
\hline Current smoker & & $39(13.0)$ \\
\hline Cigarettes per day & 39 & \\
\hline 0-10/day & & $22(56.4)$ \\
\hline$>10 /$ day & & $17(43.6)$ \\
\hline Pack-years*, median (IQR) & 31 & $24.6(13.3-36.0)$ \\
\hline Alcohol, current use & 300 & $238(79.3)$ \\
\hline Alcohol, n (\%) & 238 & \\
\hline 0-14/week & & $204(85.7)$ \\
\hline$>14 /$ week & & $34(14.3)$ \\
\hline $\begin{array}{l}\text { Items per week, median } \\
\text { (IQR) }\end{array}$ & 244 & $4(1.0-9.0)$ \\
\hline BMI, n (\%) & 300 & \\
\hline$<18.5$ & & $4(1.3)$ \\
\hline $18.5-25$ & & $119(39.7)$ \\
\hline$>25-30$ & & $122(40.7)$ \\
\hline$>30-35$ & & $35(11.7)$ \\
\hline$>35$ & & $20(6.6)$ \\
\hline BMI, median (IQR) & & $25.7(23.1-29.0)$ \\
\hline DLQI, n (\%) & 309 & \\
\hline $0-1$ & & $128(42.7)$ \\
\hline $2-5$ & & $105(35.0)$ \\
\hline $6-10$ & & $36(12.0)$ \\
\hline $11-20$ & & $30(10.0)$ \\
\hline $21-30$ & & $1(0.3)$ \\
\hline DLQI, median & & $2(1-5)$ \\
\hline
\end{tabular}

${ }^{*}$ Pack years are defined as years of smoking 20 cigarettes per day.

$\mathrm{BMI}$, body mass index; COROCO, COpenhagen ROsacea COhort; DLQI, Dermatology Life Quality Index; N, number of subjects.
Table 2 Baseline data for COMICO

\begin{tabular}{|c|c|c|}
\hline & $\mathbf{N}$ & COMICO (Migraine) \\
\hline Age, median (IQR) & 304 & $41.0(29.5-51.0)$ \\
\hline Sex, n (\%) & 304 & \\
\hline Men & & $35(11.5)$ \\
\hline Women & & $269(88.5)$ \\
\hline Migraine characteristics & 304 & \\
\hline $\begin{array}{l}\text { Migraine with aura, } \\
\mathrm{n}(\%)\end{array}$ & & $116(38.2)$ \\
\hline $\begin{array}{l}\text { Migraine without aura, } \\
n(\%)\end{array}$ & & $188(61.8)$ \\
\hline $\begin{array}{l}\text { Chronic migraine, } \mathrm{n} \\
(\%)\end{array}$ & & $116(38.2)$ \\
\hline
\end{tabular}

Family history of migraine, $n(\%)$

\begin{tabular}{|c|c|c|}
\hline Any family member & 304 & $223(73.4)$ \\
\hline First degree relative & & $193(63.5)$ \\
\hline $\begin{array}{l}\text { Second and third } \\
\text { degree relative }\end{array}$ & & $122(40$. \\
\hline
\end{tabular}

\begin{tabular}{ll}
$\begin{array}{l}\text { Family history of } \\
\text { rosacea, } \mathrm{n}(\%)\end{array}$ & 304 \\
\hline $\begin{array}{l}\text { Any family member } \\
\text { First degree relative }\end{array}$ & $56(18.4)$ \\
$\begin{array}{l}\text { Second and third } \\
\text { degree relative }\end{array}$ & $45(14.8)$ \\
\hline
\end{tabular}

Smoking, $\mathrm{n}(\%) \quad 304$

$\begin{array}{lll}\text { Never } & & 173(56.9) \\ \text { Former smoker } & & 79(26.0) \\ \begin{array}{l}\text { Current smoker } \\ \text { Cigarettes per day }\end{array} & 52(17.1) \\ 0-10 / \text { day } & & 36(69.2) \\ >10 / \text { day } & & 16(30.8) \\ \begin{array}{l}\text { Pack-years*, median } \\ \text { (IQR) }\end{array} & 10 & 12(5-21)\end{array}$

\begin{tabular}{|c|c|c|}
\hline $\begin{array}{l}\text { Alcohol, current use, } n \\
(\%)\end{array}$ & 304 & $189(62.2)$ \\
\hline Alcohol, n (\%) & 189 & \\
\hline 0-14/week & & 184 (97.3) \\
\hline$>14 /$ week & & $5(2.7)$ \\
\hline $\begin{array}{l}\text { Items per week, } \\
\text { median (IQR) }\end{array}$ & 189 & $2(1.0-3.0)$ \\
\hline BMI, n (\%) & 304 & \\
\hline$<18.5$ & & $10(3.3)$ \\
\hline $18.5-25$ & & $154(50.7)$ \\
\hline$>25-30$ & & $87(28.6)$ \\
\hline$>30-35$ & & $32(10.5)$ \\
\hline$>35$ & & $21(6.9)$ \\
\hline BMI, median (IQR) & & $24.6(21.5-28.2)$ \\
\hline DLQI, n (\%) & 304 & \\
\hline
\end{tabular}

Continued 


\begin{tabular}{|c|c|c|}
\hline & $\mathbf{N}$ & COMICO (Migraine) \\
\hline $0-1$ & & $198(65.1)$ \\
\hline $2-5$ & & $83(27.3)$ \\
\hline $6-10$ & & $17(5.6)$ \\
\hline $11-20$ & & $6(2.0)$ \\
\hline $21-30$ & & 0 \\
\hline DLQI, median & & $1(0-2)$ \\
\hline
\end{tabular}

${ }^{*}$ Pack years are defined as years of smoking 20 cigarettes per day. $\mathrm{BMI}$, body mass index; COMICO, COpenhagen Mlgraine COhort; DLQI, Dermatology Life Quality Index; IQR, Inter Quartile Range; N, number of subjects; SD, standard deviation.

with never smokers, ${ }^{36}{ }^{42}$ perhaps due to an autoimmune response, but this needs further investigation.

\section{Alcohol}

Regular intake of alcohol was seen in $79.3 \%$ of COROCO with a median average intake of 4 items/week (IQR 1.0-9.0).

Alcohol is a common trigger of flushing in patients who already have rosacea. ${ }^{45-47}$ Intake of alcohol seems to be associated with a higher risk of incident rosacea in some studies, ${ }^{40} 4849$ though other studies have failed to confirm this association. ${ }^{365051}$

\section{Body mass index}

Median body mass index (BMI) was 25.7 (23.1-29.0). Stratified into groups, underweight $(\mathrm{BMI}<18.5)$ was seen in $1.3 \%$ (4 patients), normal weight (BMI between 18.5 and 25) was found in $39.7 \%$ (119 patients), overweight (BMI between 25 and 30) was present in 40.7\% (122 patients) and obesity (BMI $>30$ ) was found in $18.3 \%$ (55 patients).

High BMI may be a risk factor for incident rosacea. ${ }^{52} 53$ Metabolic disease ${ }^{52}$ and cardiovascular comorbidities are more common in rosacea, though the causal relationship is debated. ${ }^{43} 54-56$

\section{Dermatology Life Quality Index}

Median DLQI was 2 (IQR 1-5). Stratified into groups, DLQI of 0-1 (no effect on quality of life) was present in $42.7 \%$ (128 patients). DLQI between 2 and 5 (mild effect on quality of life) was present in $35.0 \%$ (105 patients). DLQI between 6 and 10 (moderate effect on quality of life) was found in $12.0 \%$ (26 patients) and DLQI between 11 and 20 (large effect on quality of life) was found in $10.0 \%$ (30 patients). DLQI 20 (extreme effect on quality of life) was found in $0.3 \%$ ( 1 patient).

Interestingly, we find a very low impact of rosacea on daily quality of life. There may be a number of reasons for this. First, DLQI is an immediate view on the quality of life during the past week. Rosacea is fluctuating, and patients may not have had a lot of symptoms at the time of the interview, and thus a low DLQI. Second, many patients reported to have previously been very affected by their rosacea, but they were now less affected, either due to acceptance of their symptoms, or because they had been effectively treated. Third, DLQI may not be the best instrument for evaluating rosacea, as the questions are not rosacea-specific, but rather concern the whole skin, which may be why these patients have a low DLQI score, e.g., questions 3,4 and 7-10 are often not relevant in rosacea.

\section{Copenhagen Migraine Cohort \\ Age and sex}

Median age was 41 years (IQR 29.5-51.0) and 88.5\% were women.

Onset of migraine differs with age and sex, mostly affecting individuals above age 14 with a peak incidence between ages 25-34years. ${ }^{4}$ There is a strong female predominance with almost twice as many women as men being affected. ${ }^{457} \mathrm{COMICO}$ therefore resembles previous studies in migraine.

COMICO and COROCO are not intended for direct comparison and differences in age and sex between cohorts will therefore not be a problem.

\section{Family history of migraine}

Family history of migraine was found in $73.4 \%$ of those in the migraine cohort.

Previous studies have found family history reports between $54 \%$ and $77 \%{ }^{58}$. We expect that patients with migraine are more aware of their family history and believe that this might be more or less the true prevalence of family history.

\section{Family history of rosacea}

Family history of rosacea was $18.4 \%$ in the migraine cohort, corresponding to previous findings of $12 \%-17 \%$ in controls. ${ }^{36}$ As stated above, underdiagnosing of rosacea probably contributes to low family history reports in the migraine cohort as well. ${ }^{1738} 39$

\section{Smoking}

There were $17.1 \%$ current smokers in COMICO. Median pack-years were 12.0years (IQR 5.0-21.0). There were $26.0 \%$ who were former smokers.

Smoking in migraine is debated. A study from 1976 reports that smoking is unlikely to be related to migraine ${ }^{60}$ whereas more recent research found an increased risk of migraine in past and current smokers. ${ }^{61}$ Another study found that patients with migraine were more frequent and heavy smokers than their peers, ${ }^{62}$ and smoking has been suggested as a precipitating factor for migraine attacks. ${ }^{63}$

Smoking in the general population in Denmark was $23 \%$ in 2018 (22\% in women and $24 \%$ in men) ${ }^{64}$ and it thus looks like we have a lower prevalence of smoking in our cohorts than in the background population. This could be because smoking cessation may trigger either rosacea or migraine, although there is no clear evidence of this, as stated above. 


\section{Alcohol}

In COMICO, 62.2\% regularly drank alcohol, with a median average intake of 2 items/week (IQR 1.0-3.0).

Alcohol is a common trigger of migraine attacks, ${ }^{3}$ 65-68 which was also one of the most commonly anecdotally reported reasons for alcohol abstinence in this cohort.

\section{Body mass index}

Median BMI was 24.6 (IQR 21.5-28.2). Stratified into groups, underweight was seen in $3.3 \%$ (10 patients), normal weight was found in $50.7 \%$ (154 patients), overweight was seen in $28.6 \%$ (87 patients) and obesity was found in $17.4 \%$ (53 patients).

Obesity seems to be a risk factor for migraine, ${ }^{69-72}$ and obesity and weight gain contributes to worsening of migraine, with the potential of turning episodic migraine into chronic migraine. ${ }^{73-77}$ Patients for COMICO were primarily recruited through the Danish Headache Center, which is a highly specialised unit and $38.2 \%$ turned out to have chronic migraine, which may have contributed to a higher BMI in this group.

\section{Dermatology Life Quality Index}

Median DLQI was 1 (IQR 0-2). Stratified into groups, DLQI of $0-1$ was present in $65.1 \%$ (198 patients), DLQI between 2 and 5 was present in $27.3 \%$ (83 patients), DLQI between 6 and 10 was found in $5.6 \%$ (17 patients), DLQI between 11 and 20 was found in $2.0 \%$ (6 patients) and no patients had DLQI 20.

The effect on DLQI in the migraine cohort could be attributed to comorbid rosacea or other skin disorders; however, recent data suggests that DLQI in a control population is comparable to minimal disease level in patients with atopic dermatitis or psoriasis. ${ }^{78}$

\section{Future plans}

We plan for longitudinal follow-up through national Danish registers studying risk factors, occurrence, natural history, treatment, complications, comorbidities and prognosis. We also plan to invite participants for a follow-up in 10-20years.

\section{Strengths and limitations}

The COROCO and COMICO have several strengths. First, the cohorts offer phenotyping through the faceto-face interview by trained personnel, which has been shown to be the most valid way to ensure correct diagnosis of migraine, ${ }^{79}$ and for rosacea phenotyping, pictures are subsequently validated by three authors. Questions on rosacea onset and timely relationship to migraine diagnosis may prove valuable in further explaining the connection between the two. Furthermore, the comprehensive reports on rosacea features, first presenting sign/ symptom and later onset of other rosacea features may also prove valuable in determining the natural history of rosacea. Additional collected data will help in further characterising patients and possibly explaining the mechanisms behind both disorders. A major strength is the possibility of linking cohorts to the national health registers in Denmark for additional info and follow-up.

Limitations include risk of recall bias as interviews are based on patient reports of rosacea diagnosis and first presenting rosacea feature, sometimes many years prior to the interview. In those with either rosacea or migraine, there is a higher chance that they will be aware of their family history of that specific disorder, whereas they might neglect the other disorder, and a major limitation is that we will see lower family histories in those who do not have the disorder, that is, family history of rosacea in patients with migraine and vice versa. There is also a risk of selection bias, as patients were recruited primarily through specialist clinics where only the most severely affected patients are seen; however, in COROCO, we invited patients who had been seen with rosacea in the past 5 years, and their disease may have been less severe than when they came for their first visit; possibly underestimating symptoms and effect on quality of life. As patients were not excluded from one of the cohorts if they had both diagnoses, comparison between groups is also problematic as differences and similarities may be attributed to both patient groups being present in both cohorts. Furthermore, it might be speculated that patients who identified with the investigated disorders, for example, migraine patients who also identified with rosacea features, or who had family members with the disease, were more prone to accept the invitation to participate. However, we believe that the fairly short one-time studyvisit that could be combined with their outpatient visit was enough motivation in most cases. For rosacea, the disorder is relatively un-investigated, and patients seemed motivated to participate simply due to this fact.

\section{Collaboration}

For future potential collaborations and secondary use of the data, the corresponding author can be contacted after the appropriate legal approvals have been obtained.

Acknowledgements We thank all participants for their contribution to the cohorts. We thank all staff members at Rigshospitalet Glostrup and Gentofte Hospital who have contributed, and the department of Dermatology and Wound Healing at Bispebjerg hospital for contributing to this study.

Contributors NKFW, CEC, MA, AE and JPT designed the study. NKFW and DGZ collected data for the study. NKFW and JHH performed the analysis under supervision of AE. NKFW drafted the manuscript. All authors reviewed and edited the manuscript. All authors approved the final manuscript.

Funding The study was supported by grants from Novo Nordisk Foundation (NNF170C0029698) and Augustinus Foundation (17-2523).

Competing interests NKFW has received personal fees from Novartis and the $\mathrm{Kgl} \mathrm{Hofbundtmager} \mathrm{Aage} \mathrm{Bang} \mathrm{Foundation.} \mathrm{CEC} \mathrm{received} \mathrm{personal} \mathrm{fees} \mathrm{from} \mathrm{Teva}$ and acts as consultant for Teva. JHH and DGZ declare no conflicts relevant to the manuscript. MA is a consultant, speaker or scientific advisor for Alder, Allergan, Amgen, Eli Lilly, Lundbeck, Novartis, and Teva, primary investigator for Alder, Allergan, Amgen, Eli Lilly, Novartis and Teva trials. MA has no ownership interest and does not own stocks of any pharmaceutical company. MA serves as associate editor of Cephalalgia, associate editor of Headache, associate editor of the Journal of Headache and Pain. MA is President of the International Headache Society. JPT has attended advisory boards for Sanofi-Genzyme, Eli Lilly \& Co, Pfizer, Abbvie, and Union Therapeutics, and received honoraria as a speaker from LEO Pharma, Regeneron, Abbvie, and Sanofi-Genzyme, and has been an investigator for Sanofi- 
Genzyme, Eli Lilly \& Co, LEO Pharma, Pfizer, and Abbvie. AE has received research funding from Pfizer, Eli Lilly, the Danish National Psoriasis Foundation and the $\mathrm{Kgl}$ Hofbundtmager Aage Bang Foundation, and honoraria as consultant and/or speake from Almirall, Leo Pharma, Samsung Bioepis Co., Ltd. Pfizer, Eli Lilly \& Co, Novartis, Galderma, Dermavant, Bristol-Myers Squibb, and Janssen Pharmaceuticals.

Patient consent for publication Not required.

Ethics approval The study was approved by the Ethical Committee of the Capital Region of Denmark (H-17023750). All participants provided written informed consent in accordance with the declaration of Helsinki anno 1964 with adjustments until 64th WMA General Assembly, Fortaleza, Brazil, October 2013.

Provenance and peer review Not commissioned; externally peer reviewed.

Data availability statement All data are under the supervision of the corresponding author and can be made available on reasonable request.

Open access This is an open access article distributed in accordance with the Creative Commons Attribution Non Commercial (CC BY-NC 4.0) license, which permits others to distribute, remix, adapt, build upon this work non-commercially, and license their derivative works on different terms, provided the original work is properly cited, appropriate credit is given, any changes made indicated, and the use is non-commercial. See: http://creativecommons.org/licenses/by-nc/4.0/.

\section{ORCID iD}

Nita Katarina Frifelt Wienholtz http://orcid.org/0000-0003-3243-0796

\section{REFERENCES}

1 Christensen CE, Andersen FS, Wienholtz N, et al. The relationship between migraine and rosacea: systematic review and metaanalysis. Cephalalgia 2018;38:1387-98.

2 Steinhoff M, Schauber J, Leyden JJ. New insights into rosacea pathophysiology: a review of recent findings. J Am Acad Dermatol 2013;69:S15-26.

3 Kelman L. The triggers or precipitants of the acute migraine attack. Cephalalgia 2007;27:394-402.

4 Burch RC, Buse DC, Lipton RB. Migraine: epidemiology, burden, and comorbidity. Neurol Clin 2019;37:631-49.

5 Steiner TJ, Scher Al, Stewart WF, et al. The prevalence and disability burden of adult migraine in England and their relationships to age, gender and ethnicity. Cephalalgia 2003;23:519-27.

6 Lipton RB, Bigal ME, Diamond M, et al. Migraine prevalence, disease burden, and the need for preventive therapy. Neurology 2007;68:343-9.

7 Brandes JL. Global trends in migraine care: results from the maze survey. CNS Drugs 2002;16 Suppl 1:13-18.

8 Gether L, Overgaard LK, Egeberg A, et al. Incidence and prevalence of rosacea: a systematic review and meta-analysis. $\mathrm{Br} J$ Dermatol 2018;179:282-9.

9 Tan J, Berg M. Rosacea: current state of epidemiology. J Am Acad Dermatol 2013;69:S27-35.

10 Gallo RL, Granstein RD, Kang S, et al. Standard classification and pathophysiology of rosacea: the 2017 update by the National rosacea Society expert Committee. J Am Acad Dermatol 2018;78:148-55.

11 Charles A. The pathophysiology of migraine: implications for clinical management. Lancet Neurol 2018;17:174-82.

12 Vollesen ALH, Ashina M. Pacap38: emerging drug target in migraine and cluster headache. Headache 2017;57 Suppl 2:56-63.

13 Khan S, Olesen A, Ashina M. Cgrp, a target for preventive therapy in migraine and cluster headache: systematic review of clinical data. Cephalalgia 2019;39:374-89.

14 Holmes AD, Steinhoff M. Integrative concepts of rosacea pathophysiology, clinical presentation and new therapeutics. Exp Dermatol 2017;26:659-67

15 Egeberg A, Ashina M, Gaist D, et al. Prevalence and risk of migraine in patients with rosacea: a population-based cohort study. J Am Acad Dermatol 2017;76:454-8.

16 Tan SG, Cunliffe WJ. Rosacea and migraine. Br Med J 1976;1:21.

17 Berg M, Lidén S. An epidemiological study of rosacea. Acta Derm Venereol 1989;69:419-23.

18 Spoendlin J, Voegel JJ, Jick SS, et al. Migraine, triptans, and the risk of developing rosacea: a population-based study within the United Kingdom. J Am Acad Dermatol 2013;69:399-406.

19 Ramelet AA. Rosacea: a reaction pattern associated with ocular lesions and migraine? Arch Dermatol 1994;130:1448.

20 Berg M, Lidén S. Postmenopausal female rosacea patients are more disposed to react with migraine. Dermatology 1996;193:73-4.
21 WHO. ICD-10 [Internet], 2019. Available: https://icd.who.int/ browse10/2019/en

22 Rosacea. Clinical Scorecard [Internet], 2019. Available: https://www. rosacea.org/physicians/rosacea-clinical-scorecard [Accessed 2019 Jun 29].

23 Gervil M, Ulrich V, Olesen J, et al. Screening for migraine in the general population: validation of a simple questionnaire. Cephalalgia 1998;18:342-8.

24 Wienholtz N, Christensen CE, Egeberg A, et al. Vasomotor reactions in the face and head of patients with migraine.. Cephalalgia Reports. 2018;1.

25 Sinikumpu S-P, Huilaja L, Auvinen J, et al. The association between low grade systemic inflammation and skin diseases: a crosssectional survey in the Northern Finland birth cohort 1966. Acta Derm Venereol 2018;98:65-9.

26 Edvinsson L, Haanes KA, Warfvinge K. Does inflammation have a role in migraine? Nat Rev Neurol 2019;15:483-90.

27 Gormley P, Anttila V, Winsvold BS, et al. Meta-Analysis of 375,000 individuals identifies 38 susceptibility loci for migraine. Nat Genet 2016;48:856-66.

28 Chang ALS, Raber I, Xu J, et al. Assessment of the genetic basis of rosacea by genome-wide association study. J Invest Dermatol 2015;135:1548-55

29 Aponte JL, Chiano MN, Yerges-Armstrong LM, et al. Assessment of rosacea symptom severity by genome-wide association study and expression analysis highlights immuno-inflammatory and skin pigmentation genes. Hum Mol Genet 2018;27:2762-72.

30 Green RC, Berg JS, Grody WW, et al. ACMG recommendations for reporting of incidental findings in clinical exome and genome sequencing. Genetics in Medicine 2013;15:565-74.

31 Ho TW, Edvinsson L, Goadsby PJ. Cgrp and its receptors provide new insights into migraine pathophysiology. Nat Rev Neurol 2010;6:573-82.

32 Woo YR, Lim JH, Cho DH, et al. Rosacea: molecular mechanisms and management of a chronic cutaneous inflammatory condition. Int J Mol Sci 2016;17:1562-23.

33 Dodick DW, Ashina M, Brandes JL, et al. Arise: a phase 3 randomized trial of erenumab for episodic migraine. Cephalalgia 2018;38:1026-37.

34 Russell MB, Fenger K, Olesen J. The family history of migraine. direct versus indirect information. Cephalalgia 1996;16:156-60.

35 Lateef T, Cui L, Nakamura E, et al. Accuracy of family history reports of migraine in a community-based family study of migraine. Headache 2017;66:407-12.

36 Abram K, Silm H, Maaroos $\mathrm{H}-\mathrm{l}$, et al. Risk factors associated with rosacea. J Eur Acad Dermatol Venereol 2010;24:565-71.

37 Rainer BM, Fischer AH, Luz Felipe da Silva D, et al. Rosacea is associated with chronic systemic diseases in a skin severitydependent manner: results of a case-control study. J Am Acad Dermatol 2015;73:604-8.

38 Tan J, Schöfer H, Araviiskaia E, et al. Prevalence of rosacea in the general population of Germany and Russia - The RISE study. J Eur Acad Dermatol Venereol 2016;30:428-34.

39 Tizek L, Schielein MC, Seifert F, et al. Skin diseases are more common than we think: screening results of an unreferred population at the Munich Oktoberfest. J Eur Acad Dermatol Venereol 2019;33:1421-8.

40 Spoendlin J, Voegel JJ, Jick SS, et al. A study on the epidemiology of rosacea in the U.K. Br J Dermatol 2012;167:598-605.

41 Li W-Q, Zhang M, Danby FW, et al. Personal history of rosacea and risk of incident cancer among women in the US. Br J Cancer 2015;113:520-3.

42 Li S, Cho E, Drucker AM, et al. Cigarette smoking and risk of incident rosacea in women. Am J Epidemiol 2017;186:38-45.

43 Duman N, Ersoy Evans S, Atakan N. Rosacea and cardiovascular risk factors: a case control study. J Eur Acad Dermatol Venereol 2014;28:1165-9.

44 Kucukunal A, Altunay I, Arici JE, et al. Is the effect of smoking on rosacea still somewhat of a mystery? Cutan Ocul Toxicol 2016;35:110-4.

45 Weiss E, Katta R. Diet and rosacea: the role of dietary change in the management of rosacea. Dermatol Pract Concept 2017;7:31-7.

46 Bae YI, Yun S-J, Lee J-B, et al. Clinical evaluation of 168 Korean patients with rosacea: the sun exposure correlates with the erythematotelangiectatic subtype. Ann Dermatol 2009;21:243-9.

47 Elewski BE, Draelos Z, Dréno B, et al. Rosacea - global diversity and optimized outcome: proposed international consensus from the Rosacea International Expert Group. J Eur Acad Dermatol Venereol 2011;25:188-200.

48 Li S, Cho E, Drucker AM, et al. Alcohol intake and risk of rosacea in US women. J Am Acad Dermatol 2017;76:1061-7. 
49 Aldrich N, Gerstenblith M, Fu P, et al. Genetic vs environmental factors that correlate with rosacea: a cohort-based survey of twins. JAMA Dermatol 2015;151:1213-9.

50 Alinia H, Tuchayi SM, Patel NU, et al. Rosacea triggers: alcohol and smoking. Dermatol Clin 2018;36:123-6.

51 Curnier A, Choudhary S. Rhinophyma: dispelling the myths. Plast Reconstr Surg 2004:114:351-4.

52 Akin Belli A, Ozbas Gok S, Akbaba G, et al. The relationship between rosacea and insulin resistance and metabolic syndrome. Eur $J$ Dermatol 2016;26:260-4.

$53 \mathrm{Li} \mathrm{S}$, Cho E, Drucker AM, et al. Obesity and risk for incident rosacea in US women. J Am Acad Dermatol 2017;77:1083-7.

54 Egeberg A, Hansen PR, Gislason GH, et al. Assessment of the risk of cardiovascular disease in patients with rosacea. J Am Acad Dermatol 2016;75:336-9.

55 Hua T-C, Chung P-I, Chen Y-J, et al. Cardiovascular comorbidities in patients with rosacea: a nationwide case-control study from Taiwan. J Am Acad Dermatol 2015;73:249-54.

56 Dosal J, Keri J. Rosacea and cardiovascular disease: is there an association? J Am Acad Dermatol 2015;73:308-9.

57 Russell MB, Rasmussen BK, Thorvaldsen P, et al. Prevalence and sex-ratio of the subtypes of migraine. Int J Epidemiol 1995;24:612-8.

58 Hernandez-Latorre MA, Roig M. Natural history of migraine in childhood. Cephalalgia 2000;20:573-9.

59 Dzoljic E, Vlajinac $\mathrm{H}$, Sipetic $\mathrm{S}$, et al. A survey of female students with migraine: what is the influence of family history and lifestyle? Int $\mathrm{J}$ Neurosci 2014;124:82-7.

60 Volans GN, Castleden CM, Baharuddin NA. The relationship between smoking and migraine. Postgrad Med J 1976;52:80-2.

61 Hagen K, Åsberg AN, Stovner L, et al. Lifestyle factors and risk of migraine and tension-type headache. follow-up data from the NordTrøndelag health surveys 1995-1997 and 2006-2008. Cephalalgia 2018;38:1919-26.

62 Chen TC, Leviton A, Edelstein S, et al. Migraine and other diseases in women of reproductive age. The influence of smoking on observed associations. Arch Neurol 1987;44:1024-8.

63 López-Mesonero L, Márquez S, Parra P, et al. Smoking as a precipitating factor for migraine: a survey in medical students. $J$ Headache Pain 2009;10:101-3.

64 Sunhedsstyrelsen, Kræftens_Bekæmpelse, Hjerteforeningen_og_ Lungeforeningen. Danskernes rygevaner 2018 - nøgletal [Danish]
[Internet], 2018. Available: https://www.sst.dk/-/media/Udgivelser/ 2019/Danskernes-rygevaner-2018/Danskernes-rygevaner-2018_nø gletal.ashx?la=da\&hash=55335DED0545970499485950C4E375CE C5A465AF

65 Hauge AW, Kirchmann M, Olesen J. Trigger factors in migraine with aura. Cephalalgia 2010;30:346-53.

66 Panconesi A, Bartolozzi ML, Guidi L. Alcohol and migraine: what should we tell patients? Curr Pain Headache Rep 2011;15:177-84.

67 Panconesi A. Alcohol and migraine: trigger factor, consumption, mechanisms. A review. J Headache Pain 2008;9:19-27.

68 Davis-Martin RE, Polk AN, Smitherman TA. Alcohol use as a comorbidity and precipitant of primary headache: review and metaanalysis. Curr Pain Headache Rep 2017;21:42.

69 Ford ES, Li C, Pearson WS, et al. Body mass index and headaches: findings from a national sample of US adults. Cephalalgia 2008;28:1270-6.

70 Peterlin BL, Rapoport AM, Kurth T. Migraine and obesity: epidemiology, mechanisms, and implications. Headache 2010;50:631-48.

71 Vo M, Ainalem A, Qiu C, et al. Body mass index and adult weight gain among reproductive age women with migraine. Headache 2011;51:559-69.

72 Yu S, Liu R, Yang X, et al. Body mass index and migraine: a survey of the Chinese adult population. J Headache Pain 2012;13:531-6.

73 Bigal ME, Lipton RB. Obesity is a risk factor for transformed migraine but not chronic tension-type headache. Neurology 2006;67:252-7.

74 Bigal ME. Body mass index and episodic headaches. Arch Intern Med. 2007;167:1964-70.

75 Keith SW, Wang C, Fontaine KR, et al. Bmi and headache among women: results from 11 epidemiologic datasets. Obesity 2008;16:377-83.

76 Winter AC, Berger K, Buring JE, et al. Body mass index, migraine, migraine frequency and migraine features in women. Cephalalgia 2009;29:269-78.

77 Giraud P, Chauvet S, Tessy M. Migraine and obesity. is there a link ? Rev Neurol 2013;169:413-8.

78 Egeberg A, Griffiths CEM, Williams HC, et al. Clinical characteristics, symptoms, and burden of psoriasis and atopic dermatitis in adults (Epub ahead of print). Br J Dermatol 2019.

79 Rasmussen BK, Jensen R, Olesen J. Questionnaire versus clinical interview in the diagnosis of headache. Headache 1991;31:290-5. 